\title{
A Different Method in the Treatment of Placenta Previa: A Comparison of Lower Uterine Segment Transverse Suture Technique and Bakri Balloon Application
}

\author{
Gamze Savcı1 ${ }^{1}$ Ayse Z. Ozdemir¹, Pervin Karlı2 ${ }^{*}$ İdris Kocak1, Yunus Katırcı¹, Mesut Önal1 \\ ${ }^{1}$ Ondokuz Mayıs University IVF Center, Ondokuz Mayıs University Hospital, Samsun, Turkey \\ ${ }^{2}$ Department of Obstetrics and Gynecology, Amasya University, Amasya, Turkey \\ Email: gamzesavci42@gmail.com, aysezehra.ozdemir@hotmail.com, *parpi2300@hotmail.com, idrisk@omu.edu.tr, \\ yunuskatirci@msn.com
}

How to cite this paper: Savc1, G., Ozdemir, A.Z., Karlı, P., Kocak, İ., Katırc1, Y. and Önal, M. (2019) A Different Method in the Treatment of Placenta Previa: A Comparison of Lower Uterine Segment Transverse Suture Technique and Bakri Balloon Application. Open Journal of Obstetrics and Gynecology, 9, 334-342.

https://doi.org/10.4236/ojog.2019.93034

Received: January 25, 2019

Accepted: March 5, 2019

Published: March 8, 2019

Copyright $\odot 2019$ by author(s) and Scientific Research Publishing Inc. This work is licensed under the Creative Commons Attribution International License (CC BY 4.0).

http://creativecommons.org/licenses/by/4.0/

\begin{abstract}
Objective: The incidence of placenta previa (PP) has been increasing due to the rise in cesarean rates. The aim of this study is to determine the success of lower uterine segment compression suture and bakri balloon applications in patients diagnosed with placenta previa. Materials and Methods: 257 patients who underwent cesarean section due to placenta previa totalis (PPT) between the years of 2010-2018 in Ondokuz Mayıs University were screened retrospectively. The patients were evaluated in four groups according to their treatment method: medical treatment, bakri balloon application, compression suture and hysterectomy. Results: In the study, between the years 2010-2015, postpartum hysterectomy was performed in the cases of adherent placenta previa, and hysterectomy was performed in 33 patients. Between the years of 2015-2018, first, bakri balloon or compression suture was applied; and if bleeding control was not achieved despite these, then, hysterectomy was performed. Between 2015 and 2018, a total of 27 patients underwent compression suture and 1 patient had a hysterectomy after all. The success rate was 96.3\% with compression suture and $91.7 \%$ for bakri balloon application. Totally, 24 patients were treated with bakri balloon and yet, two patients underwent hysterectomy. When all the cases were examined, complications caused by urinary bladder and ureteral injury were seen in 5.6\% of patients, and all of these complications were also seen in hysterectomy patients. Conclusion: Lower uterine segment transverse suture technique and bakri balloon application should be considered as a good alternative to prevent hysterectomy in
\end{abstract}


patients with placenta previa totalis. In addition, they are effective treatment methods that can be used without increasing maternal morbidity.

\section{Keywords}

Placenta Previa Totalis, Bakri Balloon, Hysterectomy, Compression Suture

\section{Introduction}

The placenta previa, which is defined as the placement of the placenta in the lower uterine segment, happens once in 250 births [1]. It has become an important problem of obstetrics due to increased cesarean rates. Placenta accreta spectrum (PAS) disorders are the terminology, which is subdivided into creta, increta, and percreta. These diagnoses indicate the degree of invasion of the placenta to the decidua basalis and myometrium [2]. In recent years, the treatment of patients with placenta previa has been tried to be applied except for hysterectomy but there is no common treatment plan on this subject. In fact, the placenta previa involves a quite haemorrhagic and a serious process of operation. Therefore, the procedures to be performed should be the ones that can be applied very easily and in a short time. Uterine artery or hypogastric artery ligation, uterine artery embolization, compression sutures and uterine tampons are used in patients with placenta previa as fertility sparing surgery. The aim of this study is to investigate the efficacy of lower uterine compression suture technique and bakri balloon applications.

\section{Material and Methods}

257 patients with placenta previa totalis who were admitted to Ondokuz May1s University Obstetrics Clinic between 2010 and 2018 were screened retrospectively. Of these, 173 were diagnosed as non-adherent placenta previa, and 84 of them were diagnosed as adherent placenta previa (Figure 1). Diagnosis of placenta previa was made by ultrasonographic evaluation of the bladder when empty. The diagnosis of adherent placenta previa was made intraoperatively by identifying that the placenta was attached to myometrium and it could not be separated from it. This diagnosis was confirmed by pathological analysis of pathology specimen in patients who had hysterectomy. Hospital computer system records and patient files were used for data collection. The demographic data and postoperative results of the patients were recorded. In this study, the bleeding was controlled without the need for compression sutures or balloon application in all patients diagnosed with non-adherent placenta previa. Between 2010 and 2015, direct postpartum hysterectomy was performed in adherent placenta previa patients. 33 patients had hysterectomy between these years with the diagnosis of adherent placenta. Between the years of 2015 and 2018, bakri balloon application or compression suture was applied in the previa cases, and if still 
bleeding was not controlled, hysterectomy was performed. In total, compression suture was applied to 27 patients and one of them underwent hysterectomy; bakri balloon was applied to 24 patients and 2 of them underwent hysterectomy.

\subsection{Inclusion Criteria}

The study included single birth and 22-weeks-and-over pregnancies diagnosed as total placenta previa, preoperatively and postoperatively.

\subsection{Exclusion Criteria}

Patients with partial and marginal placenta previa, maternal chronic disease, preeclampsia, gestational diabetes, HELLP syndrome, bleeding diathesis, chorioamnionitis or other infectious diseases were excluded from the study as well as the cases in which decollement placenta, uterine rupture and atony developed.

\subsection{Surgical Procedure}

Lower uterine segment was dissected by lowering the bladder flap in patients undergoing lower uterine segment transverse compression suture. In the lower uterine segment, entering $2-3 \mathrm{~cm}$ below the uterine incision and passing through both uterine artery medials, it was transverse sutured so as that the needle was again coming out of the anterior wall. One or two sutures were placed one under the other. The posterior wall was also sutured transversely in itself.

Absorbable suture 'no 1 vicryl (polyglactin 910), (Ethicon) (Figure 1).

\subsection{Bakri Balloon Application}

While inserting a Bakri balloon, after the surgeon closed the uterine incision halfway, the bakri balloon was extended from the incision to the vagina and inflated with $150 \mathrm{cc}-450 \mathrm{cc}$ (according to the tamponade) test of physiological saline solution by an assistant. Then, completing the uterus incision, the operation was terminated. When bleeding control was achieved, the balloon was withdrawn gradually after 12 hours.

\section{Results}

The mean age of the patients included in the study was 32 years. The maximum number of pregnancies was 9 and the median value was 3 . The median gestational age was 253 days ( 36.1 weeks). The median cesarean count was 2, the preoperative haemoglobin value was 11.2 and the preoperative hematocrit value was 33.7 (Table 1).

The operation time varies between the groups $(\mathrm{p}<0.001)$. The median duration is 50 minutes in compression suture, $51 \mathrm{~min}$ in bakri balloon and $95 \mathrm{~min}$ in hysterectomy. The hysterectomy time was statistically higher than the others (Table 2).

Hospitalization time also varies between the groups $(\mathrm{p}<0.001)$. The median duration of compression suture is 5.3 days, 4 days for bakri balloon and 8 days 
for hysterectomy. The hysterectomy time was statistically higher than the others (Table 3). The median values of erythrocyte suspension replacement, haemoglobin decrease and hematocrit decrease values do not differ among the groups ( $\mathrm{p}$ values $0.051,0.333$ and 0.313 , respectively) (Table 4 ).

There was a significant difference between the groups in terms of the need for bilateral hypogastric artery/uterine artery ligation $(\mathrm{p}<0.001)$. Bilateral hypogastric artery/uterine artery ligation was present in $22.2 \%$ of patients with compression suture, $12.5 \%$ of those with bakri-balloon and $81.8 \%$ of those with hysterectomy (Table 5). The need for intensive care did not differ between the groups (Table 6). No statistically significant difference was observed in terms of bladder and ureter injury (Table 7). When all the cases were examined, complications were seen in $5.6 \%$ and all of these complications were seen in hysterectomy patients.

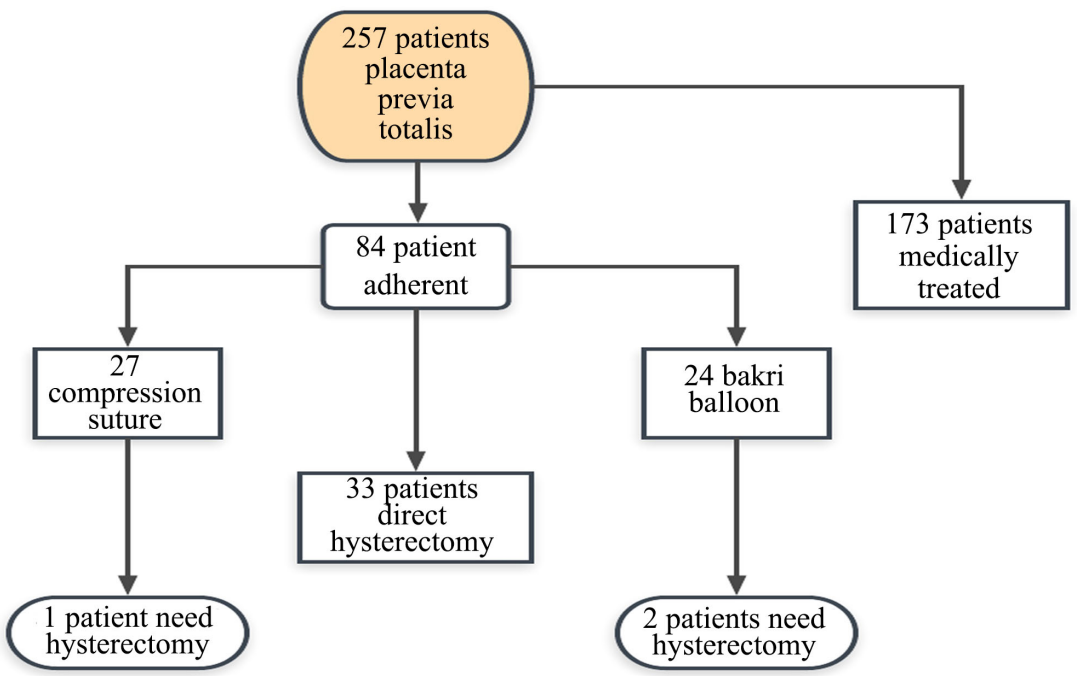

Figure 1. Summary of procedures for placenta previa.

Table 1. Descriptive statistics (n: 257).

\begin{tabular}{cc}
\hline & Median (min-max) \\
\hline Age & $32(19-50)$ \\
Pregnancy number & $3(1-9)$ \\
Pregnancy period (days) & $253(168-288)$ \\
How many cesareans? & $2(1-5)$ \\
\hline
\end{tabular}

Table 2. Comparison of operation times.

\begin{tabular}{ccc}
\hline & Median (min-max) & $\mathrm{p}$ \\
\hline Compression suture $(\mathrm{n}=27)$ & $50(40-100) \mathrm{a}$ & \\
Bakri balloon $(\mathrm{n}=24)$ & $51(45-100) \mathrm{a}$ & $<0.001$ \\
Direct hysterectomy $(\mathrm{n}=33)$ & $95(70-120) \mathrm{b}$ & \\
\hline
\end{tabular}

a, b: There is no difference between surgery types with the same letter. 
Table 3. Comparison of length of hospital stay.

\begin{tabular}{ccc}
\hline & Median $(\min -\max )$ & $\mathrm{p}$ \\
\hline Compression suture $(\mathrm{n}=27)$ & $5.3(2.7-13.9) \mathrm{a}$ & \\
Bakri balloon $(\mathrm{n}=24)$ & $4(1.7-6.7) \mathrm{a}$ & $<0.001$ \\
Direct hysterectomy $(\mathrm{n}=33)$ & $8(3.2-42.6) \mathrm{b}$ & \\
\hline
\end{tabular}

a, b: There is no difference between surgery types with the same letter.

Table 4. Comparison of erythrocyte replacement, haemoglobin and hematocrit decreases.

\begin{tabular}{cccc}
\hline & Haemoglobin decrease & Hematocrit decrease & Erythrocyte \\
\hline Compression suture $(\mathrm{n}=27)$ & $1.4(-1.8-5.4)$ & $3.8(-4.5-15.1)$ & $800(265-1600)$ \\
Bakri balloon $(\mathrm{n}=24)$ & $0.4(-3.9-5.8)$ & $1.4(-10.8-16.7)$ & $600(200-2000)$ \\
Direct hysterectomy $(\mathrm{n}=33)$ & $0.9(-12.6-12.4)$ & $2.6(-37.4-36.8)$ & $1000(200-3000)$ \\
$\mathrm{p}$ & 0.339 & 0.313 & 0.051 \\
\hline
\end{tabular}

Table 5. Comparison of bilateral hypogastric arter ligation/uterine arter ligation according to groups.

\begin{tabular}{cccc}
\hline & \multicolumn{4}{c}{$\begin{array}{c}\text { Bilateral Hypogastric Arter } \\
\text { Ligation/Uterine Arter Ligation }\end{array}$} & \\
\hline Yok & Var & $\mathrm{p}$ \\
\hline Compression suture & $21(77.8)$ & $6(22.2)$ & \\
Bakri balloon & $21(87.5)$ & $3(12.5)$ & $<0.001$ \\
Direct hysterectomy & $6(18.2)$ & $27(81.8)$ & \\
\hline
\end{tabular}

Table 6. Intensive care comparison by groups.

\begin{tabular}{cccc}
\hline & \multicolumn{3}{c}{ MYYBU } \\
\cline { 2 - 4 } & No & Yes & p \\
\hline Compression suture & $24(88.9)$ & $3(11.1)$ & \\
Bakri balloon & $20(83.3)$ & $4(16.7)$ & 0.411 \\
Hysterectomy & $25(75.8)$ & $8(24.2)$ & \\
\hline
\end{tabular}

Table 7. Bladder and ureteral injury.

\begin{tabular}{ccc}
\hline & \multicolumn{2}{c}{ Bladder and ureteral complications } \\
\cline { 2 - 3 } & No & Yes \\
\hline Compression suture & 27 & - \\
Bakri balloon & 24 & - \\
Direct hysterectomy & $25(75.8)$ & $8(24.2)$ \\
\hline
\end{tabular}




\section{Discussion}

Since the muscle layer is not sufficient in the lower uterine segment, the uterus cannot be strained and causes a large amount of bleeding from the placental bed. Placenta previa consists of creta, increta and percreta. These diagnoses indicate the degree of invasion of the placenta to the decidua basalis and myometrium [2] [3].

Nowadays, placenta previa postpartum constitutes an important role in hysterectomies. Postpartum hysterectomy is the cause of serious mortality and morbidity as well as causing loss of fertility. It is a surgery that requires serious experience in emergency situations. Operation time is longer than other applications and the risk of bladder injury is quite high. On the postpartum hysterectomy, Rossi et al. found $56 \%$ maternal morbidity and $2.6 \%$ maternal mortality in their study [4]. In addition, Michelet et al. found that $64 \%$ of patients with postpartum hysterectomy had posttraumatic stress disorder [5]. Therefore, fertility preserving surgeries have begun to come to the fore in the treatment of placenta accretain recent years [6] [7]. These are compression suture, balloon tamponade, pelvic devascularization and uterine artery embolization. Pelvic devascularization is performed in the form of connecting uterine artery or internal iliac artery. Arterial ligation can cause some complications. These complications include broad ligament hematoma, peripheral nerve ischemia, and inadvertent ligation of the lower extremity arteries [8] [9]. Uterine artery embolization should be performed by an experienced team. It is not an application performed in most centres. Bladder and uterine ischemia may occur as a complication [10].

In 1997, B-Lynch et al. first described compression suture in patients with postpartum atony [11]. Later, Hwu et al. and Hayman et al. described various compression sutures. Hwu et al. first used the compression suture in the placenta previa. Success was achieved in 14 of 14 patients (1 patient diagnosed with placenta accreta) [12] [13].

In another study, vertical compression suture was used in 15 patients with placenta previa (7 patients with placenta accreta). Only 2 patients required packing application [14]. In their study, Ratiu et al. compared 95 patients with a parallel vertical compression suture with the control group consisting of $100 \mathrm{pa}$ tients with placenta previa. They defined compression sutures as a successful surgical method for the prevention of hemostasis and uterus in patients with placenta previa. These patients were found to experience no problem with their ultrasonographic examination and menstrual periods in the long term [15]. In their study, Ying et al. performed transverse annular sutures in patients with bleeding in cesarean section due to complete placenta previa and they found that the blood transfusion and operation time in the transverse annular suture group were significantly lower than the uterine packing group [16].

Muhammed et al. applied parallel vertical compression suture technique to the patients with placenta previa. A total of 278 patients were included in the study and 171 patients underwent vertical compression suture. Successful results 
were obtained in 168 patients and only 3 patients underwent postpartum hysterectomy [17]. As to our study, 27 patients underwent lower segment transverse compression suture and only 1 patient had postpartum hysterectomy. Bilateral hypogastric artery ligation was needed in 6 patients. Of the 24 patients who underwent Bakri ballooning, only 2 patients had postpartum hysterectomy. Bilateral hypogastric artery ligation was required in 3 patients.

Intrauterine tamponade is frequently used in the treatment of postpartum haemorrhage. This may be in the form of uterine packing or can be provided with uterine balloon [18]. In 1992 Bakri made a study by first applying a large number of urinary foley catheters into the uterus [19]. Then, in 1999, Bakri presented the Bakri s.o.s (surgical obstetric silicone) balloon to be used in low line placenta and placenta previa. The success rate of the Bakri balloon was reported to be between $68 \%$ - $92 \%$ in retrospective studies [20]. There is one randomized controlled study. In this study, 52 patients with placenta previa were enrolled. In the group to whom prophylactic bakri balloon application was performed during the cesarean, less medical and surgical intervention was needed to prevent blood loss when compared to the control group. However, this difference was not statistically significant [21]. In our study, fertility preserving surgeries and hysterectomy were compared retrospectively. Since 2015, fertility protective methods have been applied in our centre. In these methods, we use the Bakri balloon and lower uterine segment transverse compression suture technique (Figure 2). One of the limitations of our study is that there is no prospective study. However, since postpartum haemorrhage is a life threatening case, it is difficult to make a prospective study. Again, one of the missing aspects is that patients who are treated with combined treatments are not present in the study. However, in our centre, only one of the Bakri balloon or compression options is sufficient in patients with postpartum haemorrhage. And as to the patients who had hysterectomy, urgent hysterectomy was needed without the time to perform uterine preserving surgery.

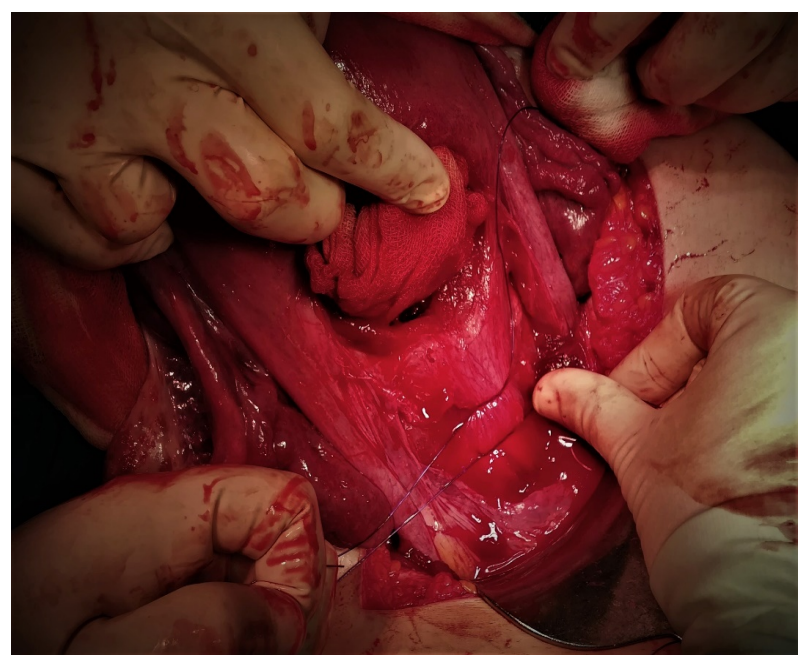

Figure 2. Lower uterine segment transverse compression suture technique. 


\section{Conclusion}

Placenta Previa is an important obstetric problem today due to the increased cesarean rates. There is still no standard treatment protocol for these patients. Hysterectomy is no longer the only option for these patients. Protection of fertility and the easy application of the method are critical in the treatment. Bakri balloon and the lower uterine segment transverse suture technique are the methods that can be applied safely and easily in these patients whose lives are at stake and who need urgent surgery. This was the retrospective study simply comparing before vs. after introduction of uterine compression suture OR Bakri balloon use.

\section{Acknowledgements}

Thank you to all those who have worked.

\section{Conflicts of Interest}

The authors declare no conflicts of interest regarding the publication of this paper.

\section{References}

[1] Selo-Ojeme, D.O. (2002) Primary Postpartum Haemorrhage. Journal of Obstetrics and Gynaecology, 22, 463-469. https://doi.org/10.1080/0144361021000003555

[2] Silver, B.M. (2015) Abnormal Placentation: Placenta Previa, Vasa Previa and Placenta Accreta. Obstetrics \& Gynecology, 126, 654-668. https://doi.org/10.1097/AOG.0000000000001005

[3] Tuzovic, L. (2006) Complete versus Incomplete Placenta Previa and Obstetric Outcome. International Journal of Gynecology \& Obstetrics, 93, 110-117.

https://doi.org/10.1016/j.ijgo.2006.02.006

[4] Rossi, A.C., Lee, R.H. and Chmait, R.H. (2010) Emergency Postpartum Hysterectomy for Uncontrolled Postpartum Bleeding: A Systematic Review. Obstetrics \& Gynecology, 115, 637-644. https://doi.org/10.1097/AOG.0b013e3181cfc007

[5] Michelet, D., Ricbourg, A., Gosme, C., et al. (2015) Emergency Hysterectomy for Life-Threatening Postpartum Hemorrhage: Risk Factors and Psychological Impact. Gynécologie Obstétrique \& Fertilité, 43, 773-779. https://doi.org/10.1016/j.gyobfe.2015.10.010

[6] Cowan, A.D., Miller, E.S. and Grobman, W.A. (2014) Subsequent Pregnancy Outcome after B-Lynch Suture Placement. Obstetrics \& Gynecology, 124, 558-561. https://doi.org/10.1097/AOG.0000000000000418

[7] Doumouchtsis, S.K., Papageorghiou, A.T. and Arulkumaran, S. (2007) Systematic Review of Conservative Management of Postpartum Hemorrhage: What to Do When Medical Treatment Fails. Obstetrical \& Gynecological Survey, 62, 540-547. https://doi.org/10.1097/01.ogx.0000271137.81361.93

[8] O'Leary, J.A. (1995) Uterine Artery Ligation in the Control of Postcaeserean Haemorrhage. Journal of Reproductive Medicine, 40, 189-193.

[9] Shin, R.K., Stecker, M.M. and Imbesi, S.G. (2001) Peripheral Nerve Ischaemia after Internal Iliac Artery Ligation. Journal of Neurology, Neurosurgery, and Psychiatry, 70, 411-412. https://doi.org/10.1136/jnnp.70.3.411 
[10] Porcu, G., Roger, V., Jacquier, A., et al. (2005) Uterus and Bladder Necrosis after Uterine Artery Ambolisation for Postpartum Haemorrhage. BJOG, 112, 122-123. https://doi.org/10.1111/j.1471-0528.2005.00306.x

[11] B-Lynch, C., Coker, A., Lawal, A.H., Abu, J. and Cowen, M.J. (1997) The B-Lynch Surgical Technique for the Control of Massive Postpartum Haemorrhage: An Alternative to Hysterectomy? Five Cases Reported. British Journal of Obstetrics and Gynaecology, 104, 372-375. https://doi.org/10.1111/j.1471-0528.1997.tb11471.x

[12] Hwu, Y.M., Chen, C.P., Chen, H.S. and Su, T.H. (2005) Parallel Vertical Compression Sutures: A Technique to Control Bleeding from Placenta Previa or Acrcreta during Caesarean Section. BJOG, 112, 1420-1423. https://doi.org/10.1111/j.1471-0528.2005.00666.x

[13] Hayman, R.G., Arulkumaran, S. and Steer, P.J. (2002) Uterine Compression Sutures: Surgical Management of Postpartum Hemorrhage. Obstetrics \& Gynecology, 99, 502-506.

[14] Li, G.-T., Li, X.-F., Wu, B., et al. (2016) Longitudinal Parallel Compression Suture to Control Postpartum Hemorrhage Due to Placenta Previa and Accrete. Taiwanese Journal of Obstetrics and Gynecology, 55, 193-197. https://doi.org/10.1016/j.tjog.2016.02.008

[15] Raitu, A.C. and Crisan, D.C. (2018) A Prospective Evaluation and Management of Different Types of Placenta Previa Using Parallel Vertical Compression Suture to Preserve Uterus. Medicine, 97, 46.

[16] Ying, H., Duan, T., Bao, Y.-R., Song, Y.-H. and Wang, D.-F. (2010) Transverse Annular Compression Sutures in the Lower Uterine Segment to Control Postpartum Hemorrhage at Cesarean Delivery for Complete Placenta Previa. International Journal of Gynecology and Obstetrics, 108, 247-257. https://doi.org/10.1016/j.ijgo.2009.10.006

[17] Magdy, A., Mohammed, M. and Mohammed, A.H. (2017) Parallel Vertical Compression Sutures to Control Bleeding in Cases of Placenta Previa and Accreta. The Journal of Maternal-Fetal and Neonatal Medicine, 82, 1476-7058.

[18] Georgiou, C. (2009) Balloon Tamponade in the Management of Postpartum Haemorrhage: A Review. BJOG, 116, 748-757. https://doi.org/10.1111/j.1471-0528.2009.02113.x

[19] Bakri, Y.N. (1992) Uterine Tamponade-Drain for Hemorrhage Secondary to Placenta Previa-Accreta. International Journal of Gynecology \& Obstetrics, 37, 302-303. https://doi.org/10.1016/0020-7292(92)90336-H

[20] Lo, A., Marie, P.S., Yadav, P., Belisle, E. and Markenson, G. (2016) The İmpact of Bakri Balloon Tamponade on the Rate of Postpartum Hysterectomy for Uterine Atony. The Journal of Maternal - Fetal and Neonatal Medicine, 220, 1476-7058.

[21] Beckmann, M.M. and Chaplin, J. (2014) Bakri Balloon during Cesarean Delivery for Placenta Previa. International Journal of Gynecology and Obstetrics, 124, 118-122. https://doi.org/10.1016/j.ijgo.2013.08.010 